This plan, of course, contemplates a one-storied, top-lighted building as far as the main rooms are concerned, although the workrooms and studies will be in two or more stories. The main rooms should all have a good substantial gallery runaing round them, by means of which their wall space is doubled. There is no question whatever that an evenly-diffused top light is far the best for exhibition rooms. Windows no: only occupy the valuable wall-space, but give all kinds of uncomfortable cross lights, interspersed with dark intervals. On the other hand, for doing any kind of delicate work, a good north light from a window, as provided in the plan, is the mos: suitable. The convenience of having all the studies in relation with each other, and with the central administrative offices, while each one is also in close contiguity with the section of the collection to which it belongs, will, I am sure, be appreciated by all who are acquainted with the capriciously scattered position of such room; in most large museums, notably in our own. Among other advantages would be the very great one that when the daily hour of closing the main building arrives, the officers need no longer, as at present, be interrupted in whatever piece of work they may have at hand, and turned out of the building, but as arrangements could easily be made for a separate exit, they could continue their labours as long and as late as they find it convenient to doso, without any fear for the safety of the general collections.

It will be observed that provision is made for a central hall, which is always a good architectural feature at the entrance of a building, and which in a museum is certainly useful in providing for the exhibition of ojjects of general interest not strictly coming under any of the divisions of the subject in the galleries, or possibly for specimens too large to be conveniently exhibited elsewhere. There is also provision in the central part of the building for the refreshment-rooms, and also for the library and a lecture room; the first being an essential, and the latter a very useful adjunct to any collection intended for popular instruction, even if no st:ictly systematic teaching should be part of its programme.

I may point out, lastly, as a great advantage of this plan, that it can be, if space is reserved or obtainable, indefinitely ex tended on both sides on exactly the same system without in any way interfering with the existing arrangements, a new section, containing exhibition and reserve galleries and studies can be added as required at either end, either for the reception of new departments, or for the expansion of the old ones. With a view to the latter it is most important that the fittings should be as little as possible of the nature of fixtures, but should all be so constructed as to $\mathrm{b}=$ readily removable and interchangeable. This is a point I would strongly impress upon all who are concerned in fitting up museums either large or small.

The modifications of this plan to adapt it to the requirements of a municipal, school, or even village museum will consi. mainly in altering the relative proportion of the two sections of the collection. The majority of museums in c suntry localities require little, if anythins, beyond the exhibition series. In this the primary arrangement to be aimed at is first, absolutely to separate the archæological, historic, and art portions of the collection from the natural history, if, as will generally be the case, both are to be represented in the museum. If possible they should be in distinct rooms. The second point is to divide each branch into two sections: $\mathbf{I}$, a strictly limited general or type collection, arranged upon a pureiy educational plan; 2 , a local collection, consisting only of objects found within a certain well-defined radius around the museum, which should be as exhaustive as possible. Nothing else should be attempted, and therefore reserve collections are unnecessary. Even the insects and dried plants can be exhibited on some such plans as those adopted for the Walsingham collection of Lepidoptera in the Zoological Department, or the collection of British plants in the Botanical Department in our Natural History Museum.

I have elsewhere indicated my views as to the objects most suitable for, and the best arrangement of them in, school museums, ${ }^{1}$ so I need say nothing further on the subject now. Indeed I fear I have exhausted your patience, so I will conclude by expresing an earnest hope that this meeting miy prove a stimulus to all of us to continue heartily and thoroughly at our work, which I need not say is the only way to ensure that general recognition of it which we all so much desire.

$$
1 \text { NatURE, vol. xli. p. 177, December 26, r889. }
$$

At the close of the address a vote of thanks was moved by Sir James Paget and seconded by Sir Henry H. Howorth. The meeting was largely attended by delegates from various pro. vincial museums, as well as by representatives of a number of museums and scientific societies in the metropolis. Among those present were Sir Joseph Fayrer, Dr. Jonathan Hutchin. son, General Festing, Lady Flower, Dr. Günther, Dr. Sclater, Dr. Henry Woodward, Mr. L. Fletcher, Mr. and Mrs. Cuthbert Peek, Mr. W. Topley, Mr. E. F. Newton, Prof. Jeffrey Bell, Mi. Osbert Salvin, Mr. F. W. Rudler, and others. The following museums were represented :-

Bootle, Bolton, Brighton, Cardiff, Chester, Dublin, Glasgow, Maidstone, Manchester, Nottingham, Parkes Museum, Saffron Walden, Sheffield, Southampton, Stockport, Sunderland, Warrington, and York.

At the conclusion of the proceedings Sir William and Lady Flower held a reception in the library of the Zoological Society.

July 4, 5, and 7 were occupied by the business of the Associa. tion. As on previous occasions, papers were read and discussed and general business transacted during the mornings; while the afternoons were devoted to the inspection of museums. The Association owes a debt of gratitude to several societies and individuals for courtesy and hospitality. The convenient rooms of the Zsological Society, at 3 II anover Square, were kindly placed at the disposal of the Association by the Council of the Society, and the Anthropological Society kindly gave the use of its library. The Council of the Royal College of Surgeons invited the members of the Association to the conversazione held at the Museum on July 5. The Royal Society and the Geological Society allowed members of the Association the privilege of inspecting their collections, and the officers of the British Museum (both at Bloomsbury and at Cromwell Road), and of the Museum of Practical Geology, conducted the members over the departments under their charge. Dr. and Mrs. Wood ward held a rcception at 129 , Beaufort Street on July 6, and Mr. Jonathan Hutchinson entertained a party at Haslemere on July 8 , and exhibited his educational museum to his guests.

\section{THE DISTRIBUTION OF MARIVE FLORAS.}

IN Phycological Memoirs, Part II., May 1893, Mr. George

Murray gives a comparative table, showing the marine floras of the warm Atlantic, Indian Ocean, and the Cape of Good Hope.

Preceding the comparison, he says:--"In delimiting the above regions I have been guided by what may fairly be taken to be their natural boundaries. The warm Atlantic is the tropical Atlantic, with a slight northward extension, to include Florida, the Bahamas, and Bermuda in the track of the Gulf Stream, and also Madeira and the Canary Islands, washed by that branch of the same stream which trend; off backward to the south, the north equatorial current. I have not included the Azores, since they are not sufficiently under this influence, and their marine flora, so far as we know it, appears to be more akin to that of the north temperate Atlantic. On its southern boundary on the African coast the Cape region is permitted to come slightly within the tropics, so far as Wallfisch Bay, on account of this coast being swept by a cold current from the south, bringing with it up to this point at all events such temperate forms as Laminaria, recently recorded from that place. The Indian Ocean similarly is the tropical Indian Ocean, but includ ing the whole of the Red Sea, and extending to the south slightly outside the tropics down the coast of Africa, and including the whole of Madagascar. I am justified in this by the course of the warm Mozambique current. I do not include on the east Sumatra, which appears to belong to another region, though I have included a few forms from the Andaman Islands and Mergui. The Cape of Good Hope region has already been indirectly described, and, as has been said, extends for the reasons given, slightly into the tropics on the west coast, and recedes slightly from that boundary on the east coast."

The table shows that the warm Atlantic has the largest recorded flora, viz. 859 species in 162 genera. I may explain that, out of this total, no less than 788 species in 150 genera occur in the West India region, and that the rest of the warm Atlantic furnishes only $7 \mathrm{r}$ species in 12 genera not occurring in the West Indies out of a much smaller total flora. Allowing for the un. doubted fact that a large number of West Indian species are

NO. I 237 , VOL. 48] 
bad species, there still remains a large balance in its favour. It has been better examined than any other part of the warm Atlantic, but still we may attiibute this preponderance mostly to the favourable natural conditions, principally the coral forma. tion of large portions of its island shores. On the coast of Africa there is not only no coral, but league after league of muddy shore, making a marine desert so far as Algæ are concerned. The Indian Ocean comes next, with 514 species in 139 genera. It possesses an enormous coast line, to a considerable extent favourable to the growth of $\mathrm{Al}_{g} æ$ (though including long desert stretches); but the bulk of the records are from Ceylon, Mauritius, and the Red Sea, while a very large proportion of the region is unexamined. As in the West Indies, there is also here a considerable proportion of bad species, principally Sargassa, from the Red Sea. From the Cape we have 429 species in $14 \mathrm{I}$ genera. This remarkalle tolal, from so short a coast line, is obtained from Niss Barton's list in the Journal of Botany, I 893. The flora previously recorded in books amounted only to 242 species in 99 genera, and this addition to its flora has resulted from her examination of the British Museum Herbarium, and her naming of the admirable collection made by Mr. Boodle, as d also those made by Mr. Scott Elliot and Mr. Tyson. The most noteworthy ol servation on these aggregates is the proportion of species to genera. In the $\mathrm{xarm}$ Atlantic the genus averages well over 5 specics; in the Indian Ocean the proportion is nearer 4 .han 3 species to the genus; while at the Cape it is almost exactly 3 . This is instructive when we remenber, as I have elseu here pointed out (Trans. Biol. Soc. Liverpoci, vol. v. p. 177), that while the Arctic Alga average slightly more than 2 species only to the genus, the West Indies and Australia average rather more than 5 and less than 5 respectively. I estimate that the north temperate Atlantic yields an average of about $4 \frac{1}{2}$ species to the genus, and the difference between this and 3 species per genus found at the Cape is to be attributed primarily to the short coast line of the Cape, and in a less degree to its Algæ being less known. The calculation of such averages and proportions appears to me to be justified only when applied to the whole flora, and becomes more dangerous and apt to mislead when applied to portions of it, since particular groups in all the flot as have been subjected to unequal treatment by collectors and describers, and we may perhaps trust to these personal errors neutralising each other when the complete totals are compared.

The warm Allantic and Cape have 85 genera and I 44 species in common, while the Indian Ocean and Cape have 86 genera and 89 species in common. That the number of genera in common should be so nearly exactly similar is interesting, and to discover whether they are the same genera in many cases it is only necessary to turn to the last table, where the $\mathrm{Al}_{\mathrm{b}}$ : common to all three regions are given to find that 72 genera are common to all three. Some years ago I hazarded the speculation that, while the genera of the tropical Atlantic and those of the Indian Ocean were largely the same, the species were, in a high proportion, different ("Catalogue of Marine Algx of the West Indian Region"). We can now see that they have no less than ro3 genera in common out of a total of 139 occurring in the Indian Ocean and 162 in the warm Atlantic. They have certainly more species in common, viz. 173 , but these must be considered relatively to the two totals of $5 \mathrm{I}_{4}$ in the Indian Ocean and 859 in the warm Atlantic, when my expectation will appear to be fairly borne uut. Nevertheless, I confess to having anticipated an even greater diversity of species. That the absolute number of genera occurring at the Cape should be by two greater than those of the Indian Ocean com. pletely puzzles me. I cannot fully account for it on any theory. While the number of species in common between any two of the floras is greater than the number of genera (though in one case only three more), the number of species, as might be expected, in common to all three-viz. 59-is less than the genera-viz. 72. Again I should have expected to find relatively fewer species in common.

When one comes to analyse these totals, the process must be carried on in a more guarded fashion. One expects, as shown above, to find fewer species to the genus at the Cape than in the tropical foras, but one hardly expects to find that the genera of Floridea at the Cape are by five more numerou; than in the warm Atlantic, and by 15 more than in the Indian Oeean. There are no less than 95 genera of Floridece at the Cape, with 295 species, while the go of the warm Atlantic contain nearly 200 niore species! Matters are much the same in the case of the Phoo- phy'ca, and we have come to the Chlorophycece to redress the balance in the case of the wam Atlantic. They just fail to brirg it level in the case of the Indian Ocean. It has teen remarked above that the genera which the two tropical floras have in common with the Cape are almost identical in number. The analysis shows that the figures are very steady, viz. 58 each of Floridice, 14 and 15 of Phasphyica, II each of Chlorophycca, and two each of Frotophycia. The lable sbows the tropical character of such a group as the Siphonca very markedly. There are 99 species in 23 genera in the warm Atlantic, 72 species in 16 genera in the Indian Ocean, and cnly 20 species in 7 genera at the Cape. It is interesting to observe that the whole of the I6 genera of Siphonice in the Indian Ocean are represented in the warm Atlantic. It has no peculiar generic type of its cwn in this tropical group. While the genera of this iropical order are thus practically identical, the species are in a very high proportion different. Only 29 are possessed in common out of the two totals of 99 and 72 . In the comparison of the tu o tropical floras there is the coir.cidence that the genera and species of Siphonea agree (xactly in numbers, viz. 16 and 29 , with the total of all the Phcophycca-a thing without sionificance, bow ever.

The interest that is attached to the above comparison is mainly this. We have here two tropical marine floras cut off from each $o$ : her by a permanent continental area, and communica ing only viâ the Cape. That these floras have been peiciodically mingied at the epochs of warmer climate at the Cape seems a reasonable conclusion with regard to $a$ group of such antiquity as the Algæ, and the proportions of species in cummon and genera in common between the different regions, and among all three may have a significance in this respect to students of di:tribution ( $f$. the totals of Ciphonee, a peculiarly tropical order). I have elsewhere (Trans. Biol. Soc. Liverpoul, vol. v. p. I78) commented on the fact that, "while in the Arctic and Australian regions the Pliaofhycce far outnumber the Chlorophyca, in the tropical West Indian flora the proporition is very markedly reversed, and the green Alsæ (utnumber the olive-broun. One is tenipted to put this dow $n$ to the strong illumination of the tropical sea, but a nother reasc $n$ is 10 be found in the fact that a number of the Antilles richest as regards $A I_{\delta} æ$ are subject to irruptions of fresh and hrackish $n$ ater ficm the Orinoco flocds-a condition that would operate in the same direction." We can now check this speculation ly a comparison with the figures for the Indian Ocean, mainly derived from such localities as the Red Sea, Ceylon, Mauritius, \&c, in no case affected by the question of fresh-uater floods. The figures for the Indian Ocean are very nearly the same for both groups-24 genera and II 7 species of Phaophycia, and 26 genera and 121 species of Chlorophyciathus showing indircclly that the irruptions of fresh water are, in all probalility, potent in the case of the West Indian Algr. One is much struck by the strength of illumination of the bottom in a shallow coral sea, $l$ ut the filtering action by sea water of the rays of light, and the interception first of those rays that are most $\mathrm{efficient}$ in the work of assimilation-conditions modifying the pigments of Alsr-ate the same in all seas. ${ }^{1}$ The practically tideless character of the Antilles would also make for a preponderance of green over olive-brown forms.

\section{UNIVERSITY AND EDUCATIONAL INTELLIGENCE.}

THE Bristol Medical School, which was established early in this century, has, since the establish ment of University College, Bristol, about severteen years ago, been affiliated to it, but remaired uncer the direction of a separate governing body. Within the last few months the two institutions have been amalgamated and placed under one Ccuncil, and the Medical School now constitutes the faculty of medicine in the College.

THE Council of University College, Bristol, have raised to the status of Professor, in the Faculty of Arts and Science, Mr. F. R. Barrell, Lecturer in Mathematics, and Mr. A. P. Chattock, Lecturer in Physics, and have also appointed Ir. Edward Fawcett, late Senior Demonstrator of Anatomy in the Yorkshirt College, Leeds, to the Professorship of Anatomy in the Faculty of Medicine.

1 Fecent reseatch on other pigments by Prof. Marshall Ward makes $j$ aprear to me rore prubable that, in the case of the marine Algæ, the pig ments are rather shields against the excess of blue rays than adaptations 10 heighten the susceptibility of chlorcphyll to the diminished surply of the others. 